\title{
TESTES DE SEDIMENTAÇÃO COM FINOS DE VERMICULITA
}

\author{
A. C. SILVA ${ }^{1 *}$, E. M. S. SILVA ${ }^{1}$, J. VAZ e T. M. SILVA ${ }^{2}$ \\ ${ }^{1}$ Universidade Federal de Goiás, Laboratório de Modelamento e Pesquisa em Processamento Mineral \\ (LaMPPMin) \\ ${ }^{2}$ Engenheiro de Minas, Brasil Minérios. \\ ancarsil@ufg.br*
}

Artigo submetido em julho/2015 e aceito em agosto/2015

DOI: 10.15628/holos.2015.3201

\section{RESUMO}

A vermiculita é um silicato hidratado de formato lamelar, que possui quantidades variáveis de ferro, potássio e alumina, possuindo usos como isolante acústico, térmico, agregado leve para produção de concretos especiais, proteção passiva contra fogo, refratários industriais de fricção (pastilhas de freio) e componentes de substratos agrícolas para horticultura e produção de mudas etc. A Brasil Minérios é a maior produtora de concentrado de vermiculita da américa latina, com exportações para mais de 10 países, além de ser líder do mercado brasileiro de vermiculita expandida. A Brasil Minérios comercializa três produtos, em frações granulométricas acima de $0,3 \mathrm{~mm}$ (50\# $A B N T$ ) sendo dividido em médio (+ 2,0 mm), fino ($2,0+1,0 \mathrm{~mm})$, ultrafina $(-1,0+0,5 \mathrm{~mm})$ e mícron $(-0,5+0,3$ $\mathrm{mm}$ ), sendo que o material abaixo de $0,3 \mathrm{~mm}$ é considerado como lama e mandado para a barragem de rejeitos. O objetivo do presente trabalho é espessar o material abaixo de $0,3 \mathrm{~mm}$ de modo a enviá-lo para a barragem de rejeitos com maior porcentagem de sólidos, testando quais as melhores condições para sedimentação deste em provetas de 2,0 L variando $\mathrm{pH}$, tipo e dosagem do floculante. Foram testados três tipos diferentes de poliacrilamidas uma aniônica, uma catiônica e uma não iônica. Como resultados foram medidos a altura da zona compacta, e a turbidez do líquido clarificado gerado. Os resultados encontrados mostraram que o Magnafloc 351, uma poliacrilamida não iônica, foi o floculante que gerou a menor zona compacta, em pH 7 e dosagem de $45,6 \mathrm{~g} / \mathrm{t}$

PALAVRAS-CHAVE: sedimentação, vermiculita, floculação.

\section{SEDIMENTATION TESTS WITH FINE VERMICULITE}

\begin{abstract}
Vermiculite is a hydrated silicate lamellar format, which has variable amounts of iron, potassium and alumina, possessing use as acoustic insulation, thermal, lightweight aggregate for producing special concrete, passive fire protection, industrial refractory friction (brake pads) and components of agricultural substrates for horticulture and seedling production etc. The Brasil Minérios sells three products, in soil fractions above 0.3 $\mathrm{mm}$ (50\# ABNT) and divided into average (+ $2.0 \mathrm{~mm})$, thin $(-2.0+1.0 \mathrm{~mm})$, ultrafine $(-1.0+0.5 \mathrm{~mm})$ and micron $(-0.5+0.3 \mathrm{~mm})$, while the material below 0.3 $\mathrm{mm}$ is regarded as slurry and sent to the tailings dam.
\end{abstract}

The objective of this study is thicken the material below $0.3 \mathrm{~mm}$ in order to send it to the tailings dam with higher solid percentage, testing which better conditions for settling this in beakers of $2.0 \mathrm{~L}$ varying $\mathrm{pH}$, type and dosage of flocculant. We tested three different types of polyacrylamides an anionic, a cationic and a non-ionic. Results were measured as the height of the compact zone and the turbidity of the clarified liquid generated. The results showed that the Magnafloc 351, a non-ionic polyacrylamide flocculant was lower that generated the compact zone in dosage $\mathrm{pH} 7$ and $45.6 \mathrm{~g} / \mathrm{t}$.

KEYWORDS: sedimentation, vermiculite, flocculation. 


\section{INTRODUÇÃO}

Segundo Ugarte et al. (2005) a vermiculita é um silicato hidratado de magnésio, alumínio e ferro com uma estrutura micáceo-lamelar possuindo uma faixa de composições, que depende, da composição da mica que a gerou, da variação química durante o intemperismo e da troca iônica durante o processo de formação. Este nome deriva do latim vermiculus significando pequeno verme, isto devido ao fato de que esse material se expande sob aquecimento, no qual suas partículas se movem de forma parecida com a dos vermes.

Seu valor comercial está relacionado a essa característica de expansão térmica, pois na forma expandida ela é quimicamente ativa, biologicamente inerte e possui baixa densidade, conferindo-lhe inúmeras aplicações industriais em áreas distintas como construção civil, agricultura, indústrias químicas, de tinta, entre outras. Segundo Paula (2014) os quatro maiores produtores de vermiculita do mundo concentram $80 \%$ da produção mundial, sendo que a líder do ranking é a África do Sul, com $29,9 \%$ da produção, em seguida vem os Estados Unidos com $23 \%$, e o Brasil vem na terceira colocação com $15,6 \%$ da produção mundial. Dentre os estados produtores da vermiculita no Brasil, Goiás com $85 \%$ da produção, Pernambuco com 4,2\%, Paraíba com 7,8\% e Bahia com 2,5\% foram responsáveis pela produção de 68.014 toneladas de vermiculita beneficiada em 2013.

A Brasil Minérios e Empreendimentos, vem há cerca de 40 anos realizando atividades de lavra, processamento, industrialização e comercialização de concentrado de vermiculita e produtos de sua cadeia de verticalização destinados aos setores agrícola, construção civil, siderúrgico, indústria de veículos, moldados, nutrição animal, entre outros. Através de atividades de mineração e industrialização, ela está capacitada a produzir em suas minas e parques industriais, localizados no estado de Goiás, montantes da ordem de 100.000 t de concentrado de vermiculita por ano, inserindo-se entre os grandes produtores mundiais de vermiculita. $O$ concentrado da Brasil Minérios, é comercializado em frações granulométricas acima de 0,3 $\mathrm{mm}$ (50\# ABNT) sendo dividido em médio $(+2,0 \mathrm{~mm})$, fino $(-2+1 \mathrm{~mm})$, ultrafina $(-1,0+0,5 \mathrm{~mm}) \mathrm{e}$ mícron $(-0,5+0,3 \mathrm{~mm})$, e as frações abaixo dessas granulometrias citadas vão para o rejeito. 0 processamento da vermiculita consiste primeiramente da lavagem do ROM, na etapa posterior, o material passa por uma grelha de 4", no qual fragmentos maiores devem ser quebrados ou retirados. Após isso o material vai para uma peneira denominada de "despedradora", retirandose fragmentos de rocha maiores que sua abertura, para após ser moído e lavado novamente para retirada de argila. A seguir o material moído é classificado em granulometria adequada e o produto resultante é levado para trommels para lavagem final. Depois da lavagem nos trommels o produto é levado à um pátio para secagem, sendo revolvido em intervalos periódicos para otimizar o processo, onde após essa secagem em pátios o material é levado à fornos havendo a secagem total, auxiliada por queimadores a gás. O produto dessa secagem alimenta duas peneiras vibratórias inclinadas, no qual o retido na malha de $4 \mathrm{~mm}$ volta para moagem e o material retido nas demais $(2,362 ; 1,168 ; 0,595$ e $0,420 \mathrm{~mm})$ vai para a expedição do produto em big bags, de acordo com a granulometria do mesmo.

Dentro deste contexto o objetivo deste trabalho foi analisar o comportamento da sedimentação das frações não comercializáveis, ou seja, abaixo de $0,3 \mathrm{~mm}$, visando um melhor reaproveitamento da água utilizada no processo de beneficiamento, pois nos dias atuais a água é um bem de extrema importância e que não deve ser desperdiçado. Para tal foram utilizados 
floculantes que, segundo França e Massarani (2010) podem ser definidos como polímeros orgânicos responsáveis por criar pontes entre as partículas de uma suspensão, permitindo um aumento no seu diâmetro efetivo e, consequentemente, nas taxas de separação sólido-líquido.

\section{MATERIAL E MÉTODOS}

A vermiculita foi seca em estufa de secagem a $80{ }^{\circ} \mathrm{C}$ por 5 horas. Após a secagem a vermiculita foi submetida a peneiramento seco em um peneirador suspenso, sendo que o passante em 0,3 $\mathrm{mm}$ (50\#) foi separado para a realização dos testes de sedimentação em proveta de 2,0 L. De modo a preparar polpas a serem testadas com $15 \%$ de sólidos em peso, porcentagem trabalhada na empresa, a massa específica da vermiculita foi determinada utilizando-se um picnômetro de vidro de $100 \mathrm{~mL}$ de volume interno. A vermiculita passante em $0,3 \mathrm{~mm}$ (50\#) foi homogeneizada e posteriormente quarteada em um quarteador tipo Jones para a obtenção de massas de $326,7 \mathrm{~g}$, sendo tais massas utilizadas para cada um dos testes em proveta de $2,0 \mathrm{~L}$.

Os testes foram realizados com e sem a adição de floculantes, onde os mesmos estavam em uma concentração de $0,5 \% \mathrm{~m} / \mathrm{m}$ e as dosagens utilizadas foram de 1,$5 ; 3,0$ e 4,5 mL/L (ou 22,$8 ; 45,6$ e 68,4 g/t respectivamente). Para a execução dos ensaios de sedimentação foi seguida a metodologia descrita por Svarovsky (1981) e por França e Casqueira (2007). As amostras com $326,7 \mathrm{~g}$ de vermiculita passante em $0,3 \mathrm{~mm}$ foram colocadas nas provetas de $2,0 \mathrm{~L}$, sendo então adicionada água fornecida pela Brasil Minério Ltda até o volume total da proveta $(2,0 \mathrm{~L})$. A polpa foi homogeneizada com 4 golpes de um agitador de provetas, sendo iniciada a marcação do tempo de sedimentação ao final do 4o golpe, aciona-se o cronômetro para marcação do tempo do ensaio. O deslocamento da interface sólido/líquido se deu com maior velocidade na etapa inicial do teste, chamada de etapa de sedimentação livre, por isso, a altura foi anotada pelo operador em intervalos de tempos pré-estabelecidos, de 30 segundos. Ao final do ensaio, quando a maioria das partículas já sedimentou e ocorre apenas o empacotamento do leito de sólidos no fundo da proveta, percebe-se que a variação de altura da interface se dá muito lentamente, então a partir de 10 min o intervalo de tempo de observação foi aumentado, até ocorrer a estabilidade no valor da altura da região de compactação de sólidos, ou que esta varie muito pouco em um grande intervalo de tempo. A duração total de cada teste foi de duas horas. $\mathrm{O}$ pH da polpa, quando necessário, foi corrigido pela adição de solução de ácido clorídrico 0,5 N, sendo medido em um pHmetro de bancada Hanna modelo HI 2221.

Ao final do teste uma amostra do líquido clarificado gerado foi coletada para análise de turbidez da mesma, em um turbidímetro portátil da Hanna modelo HI 93703. Foram realizados 32 ensaios, onde foram testadas três dosagens, já citadas anteriormente em três valores de pH diferente sendo estes 5, 6 e 7 e com a adição de três tipos de floculantes, o Superfloc A-100, Superfloc C-492 e Magnafloc 351. A tabela 1 apresenta a caracterização dos floculantes utilizados. 
Tabela 1 - Características do floculantes utilizados.

\begin{tabular}{c|c|c|c}
\hline Floculante & Superfloc A-100 & Superfloc C-492 & Magnafloc 351 \\
\hline Massa específica $\left(\mathrm{g} / \mathrm{cm}^{\mathbf{3}}\right)$ & 0,8 & 0,75 & 0,7 \\
Viscosidade a 0,5\% (cP) & 500 & 450 & 100 \\
Polímero & Poliacrilamida & Poliacrilamida & Poliacrilamida \\
Carga do Polímero & Aniônica & Catiônica & Não iônica \\
Peso molecular & Alto & Alto & Alto \\
Fabricante & Kemira & Kemira & Basf \\
\hline
\end{tabular}

\section{RESULTADOS E DISCUSSÃO}

A massa específica média da vermiculita determinada via picnometria foi de $2,2 \mathrm{~g} / \mathrm{cm}^{3}$. Este valor está em acordo com a literatura (MACHADO et al., 2015), que traz valores entre 2 e 3 $\mathrm{g} / \mathrm{cm}^{3}$. A figura 1 apresenta os resultados da variação da camada compacta em relação ao tempo de sedimentação para pH 5. Nota-se que a adição de floculante em todas as dosagens testadas fez com houvesse um ganho significativo na sedimentação, ou seja uma diminuição da camada compacta, da ordem de $340 \%$ em média em relação ao teste feito sem a adição de floculante, sendo que o mais significativo foi para uma dosagem de 91,2 g/t do floculante Magnafloc 351 o qual obteve-se um ganho de $558 \%$ em comparação ao teste sem a adição de reagente.

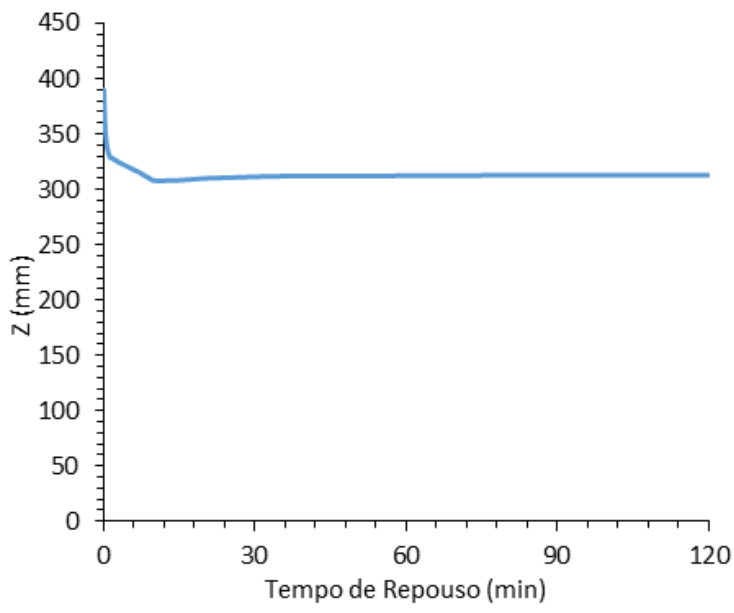

(a)

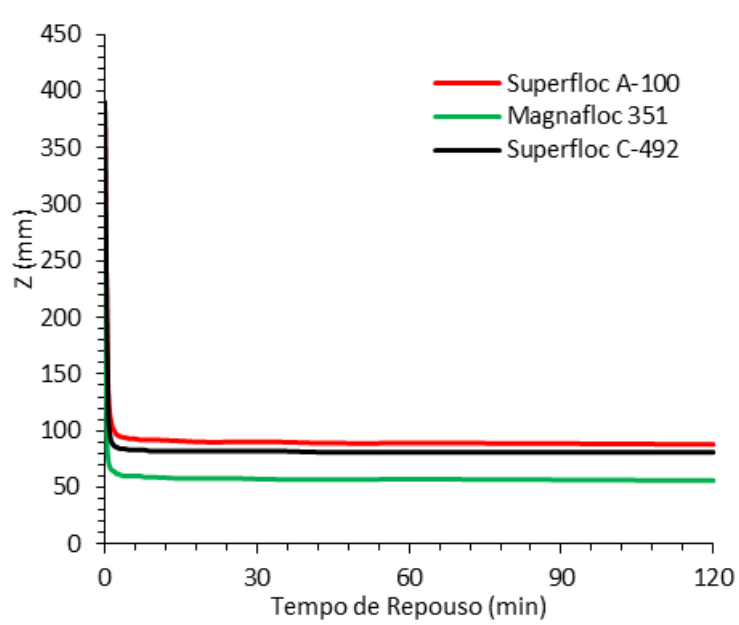

(c)

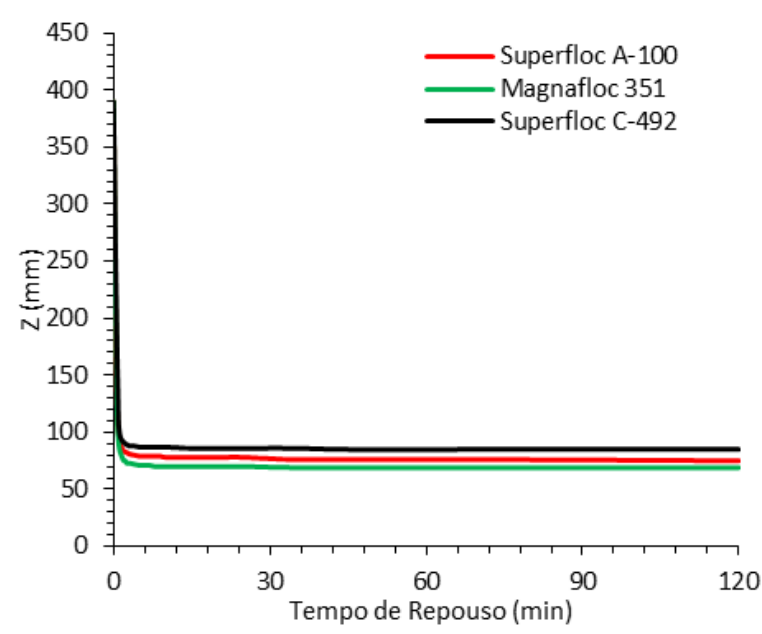

(b)

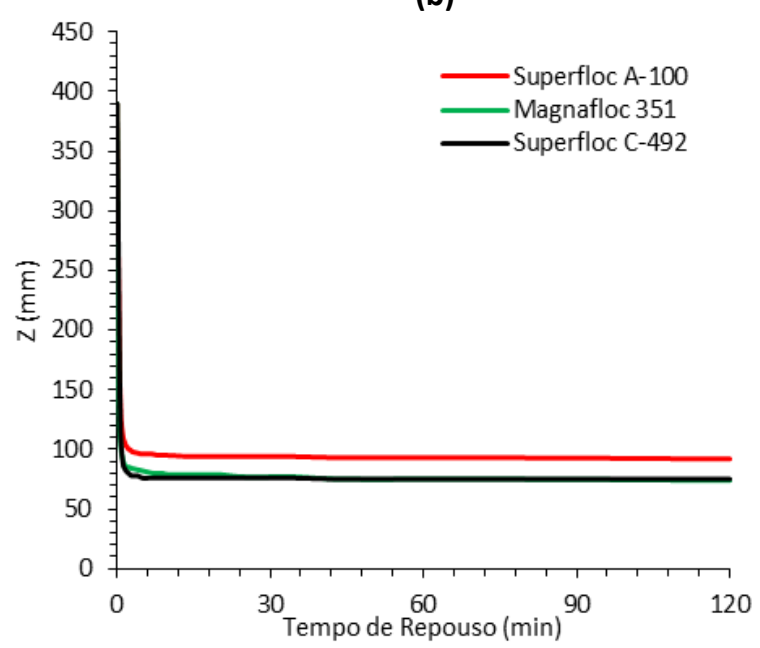

(d)

Figura 1. Variação da camada compacta em relação ao tempo de sedimentação para pH 5. (a) sem floculante, (b) 45,6 , (c) 91,2 e (d) $136,8 \mathrm{~g} / \mathrm{t}$ de floculante. 
A figura 2 apresenta os resultados da variação da camada compacta em relação ao tempo de sedimentação para pH 6, na qual novamente observou-se um aumento da sedimentação com a adição dos agentes aglomerantes, da ordem de $405 \%$ em média em comparação com o teste sem adição de floculante. Onde o resultado mais expressivo foi novamente na dosagem de 91,2 $\mathrm{g} / \mathrm{t}$ usando o Magnafloc 351 obtendo-se um aumento de $478 \%$ comparado ao sem a adição do mesmo.

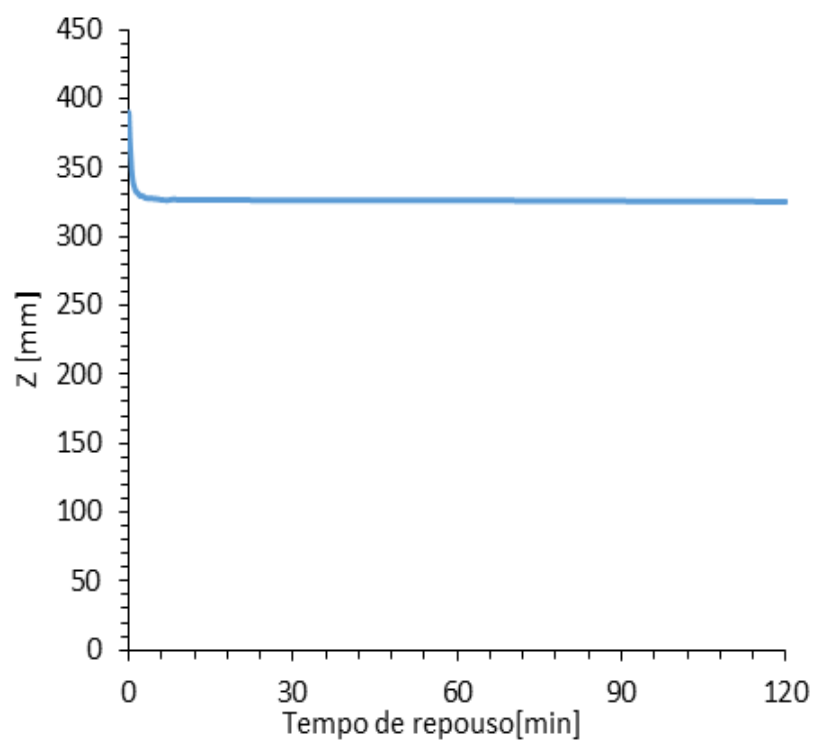

(a)

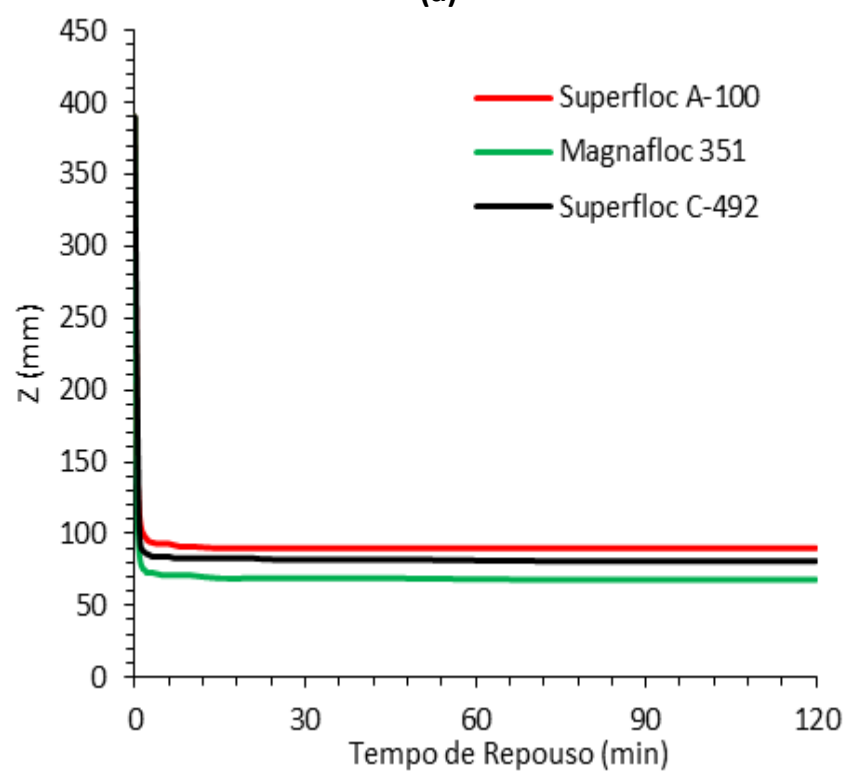

(c)

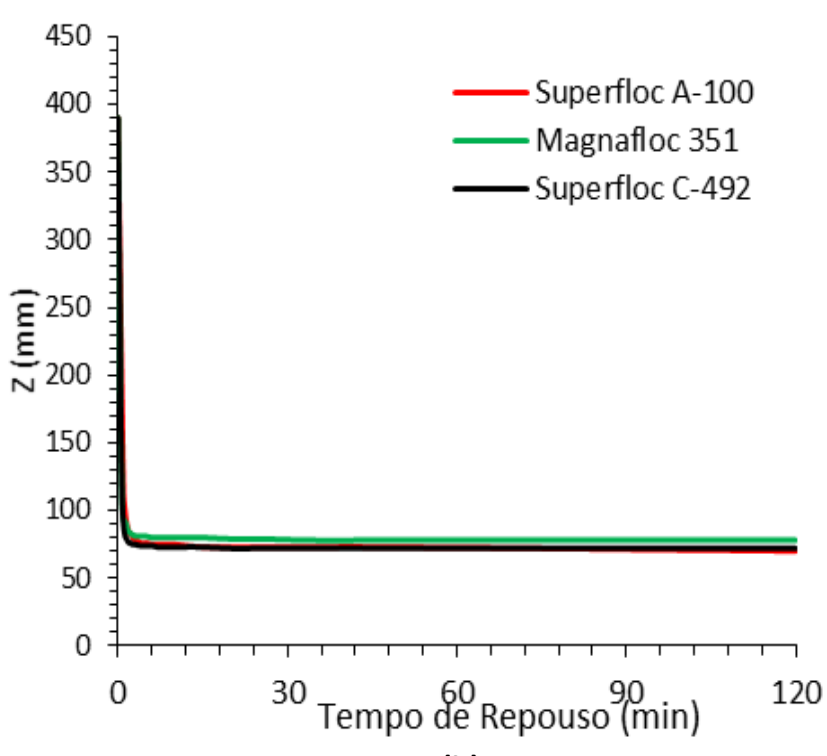

(b)

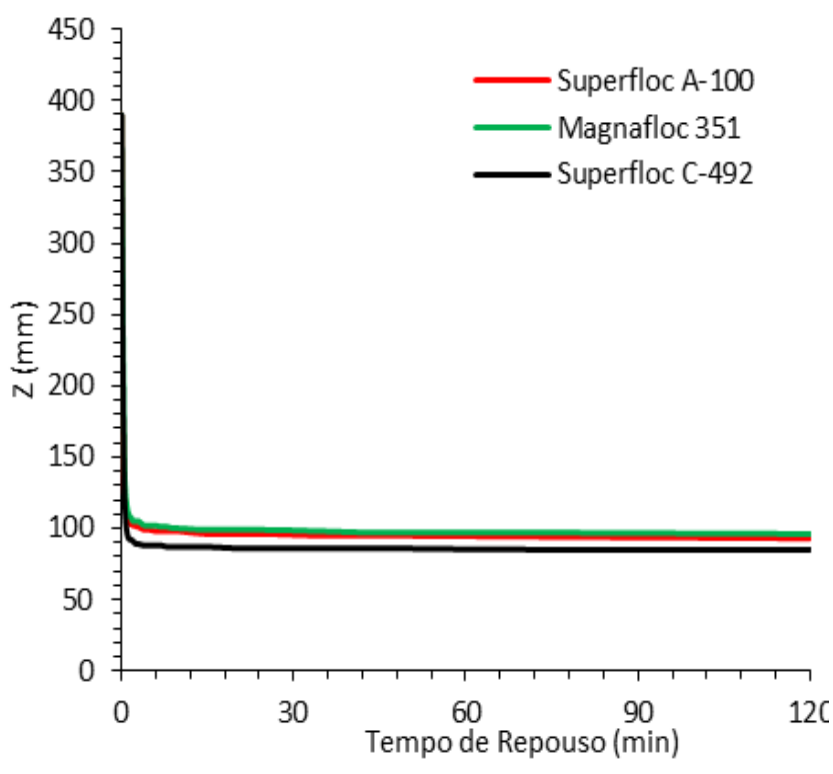

(d)

Figura 2. Variação da camada compacta em relação ao tempo de sedimentação. Para pH 6 a) sem floculante, (b) $45,6 \mathrm{~g} / \mathrm{t}$ (c) $91,2 \mathrm{~g} / \mathrm{t}$ (d) $136,8 \mathrm{~g} / \mathrm{t}$

A figura 3 apresenta os resultados da variação da camada compacta em relação ao tempo de sedimentação para pH 7 sendo obtido, assim como nas condições anteriores um ganho relevante na sedimentação de $420 \%$ em média comparando-se ao teste sem floculante. Sendo que nesta condição de teste obteve-se os melhores resultados de proporção de ganho em relação ao sem floculante, obtido nas dosagens $45,6 \mathrm{~g} / \mathrm{t}$ e $91,2 \mathrm{~g} / \mathrm{t}$, chegando a $604 \%$. 


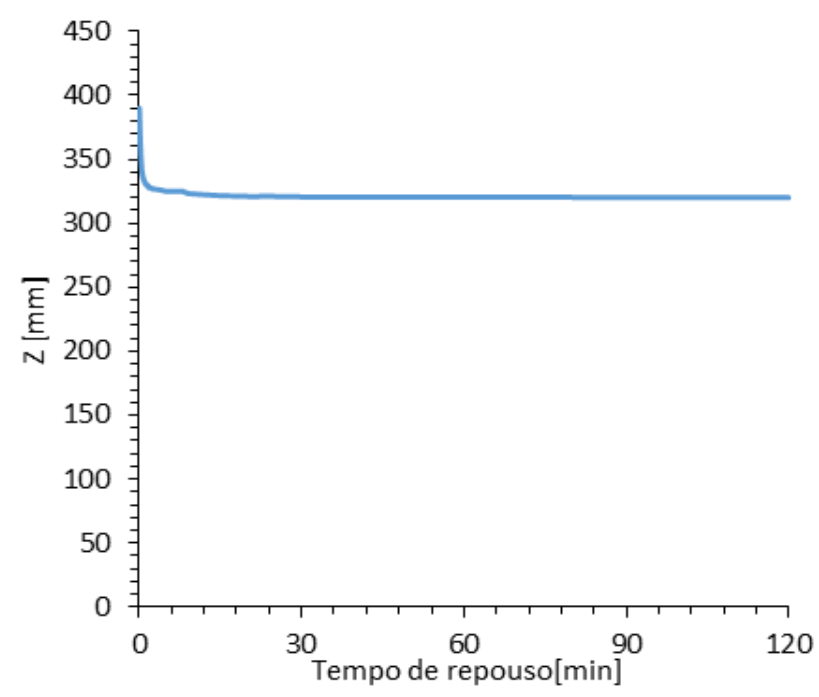

(a)

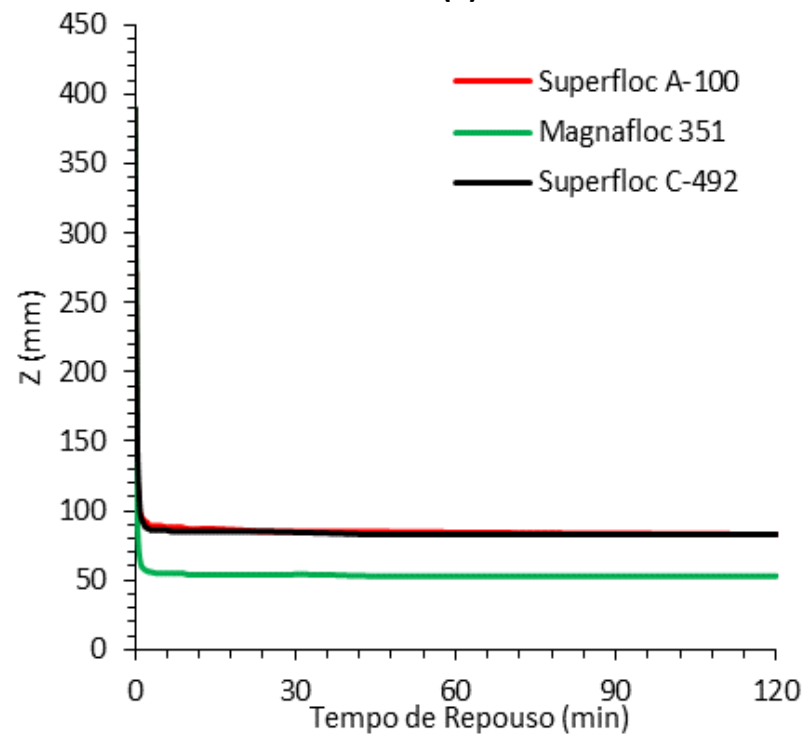

(c)

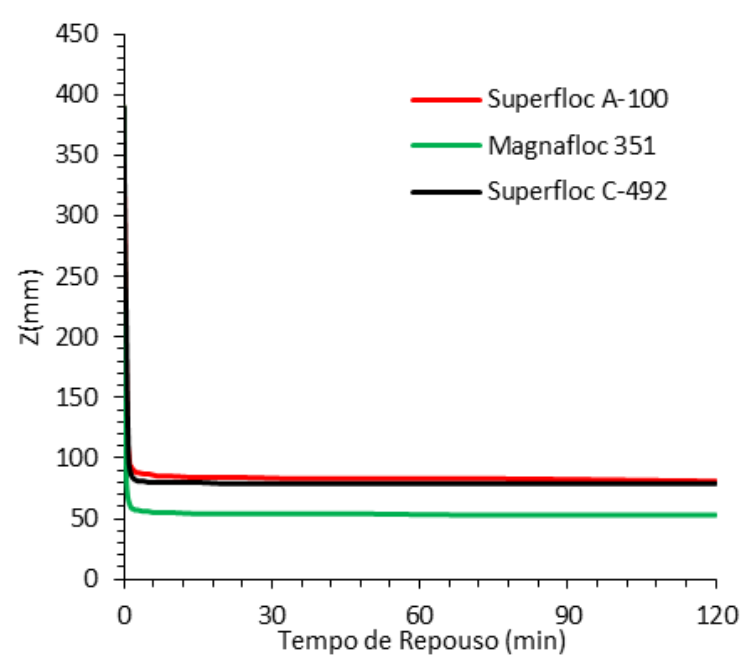

(b)

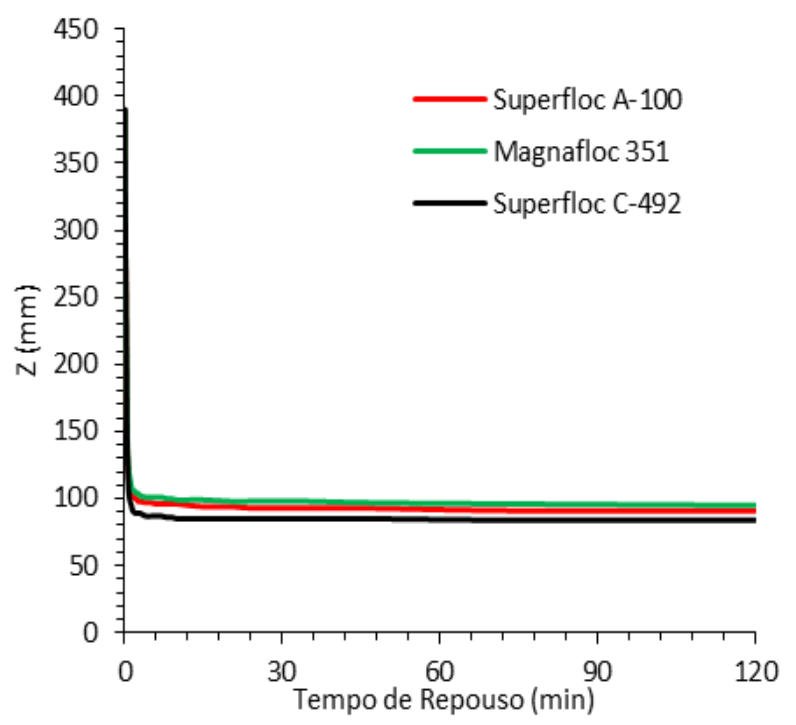

(d)

Figura 3. Variação da camada compacta em relação ao tempo de sedimentação para pH 7 (a) sem floculante, (b) $45,6 \mathrm{~g} / \mathrm{t}$ (c) $91,2 \mathrm{~g} / \mathrm{t}$ (d) $136,8 \mathrm{~g} / \mathrm{t}$

A figura 4 demonstra os valores encontrados para a turbidez, dado as diversas condições testadas. Segundo a resolução do Conama no 357/2005 os valores aceitaveis de turbidez para aguas doces classe I ( destinadas ao abastecimento para consumo humano com desinfecção, à preservação do equilíbrio natural das comunidade aquáticas, e à preservação dos ambientes aquáticos em unidades de conservação de proteção integral) são de até 40 NTU (unidades nefelométricas de turbidez), sendo que como meta propria definimos um padrão da ordem de 10 NTU como limite máximo aceitavel. Diante disso as únicas condições que não atendem ao limite imposto são, nas dosagens 45,6 g/t no pH 5 e 7 para o Superfloc C-492, 45,6 g/t no pH 6 e 91,2 $\mathrm{g} / \mathrm{t}$ no $\mathrm{pH} 7$ para o Magnafloc 351. Sendo que os melhores resultados obtidos foram com a utilização do Superfloc A-100, encontrando valores menores do que 1,0 NTU. 


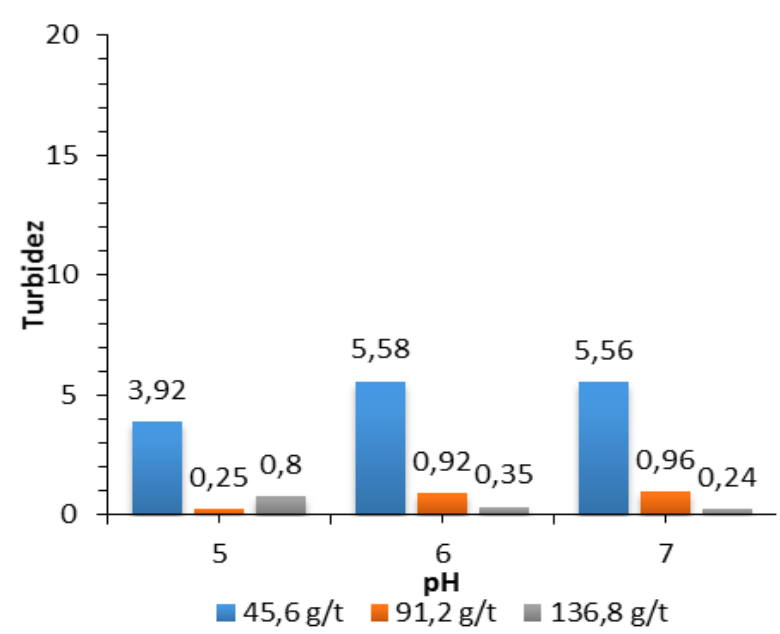

(a)

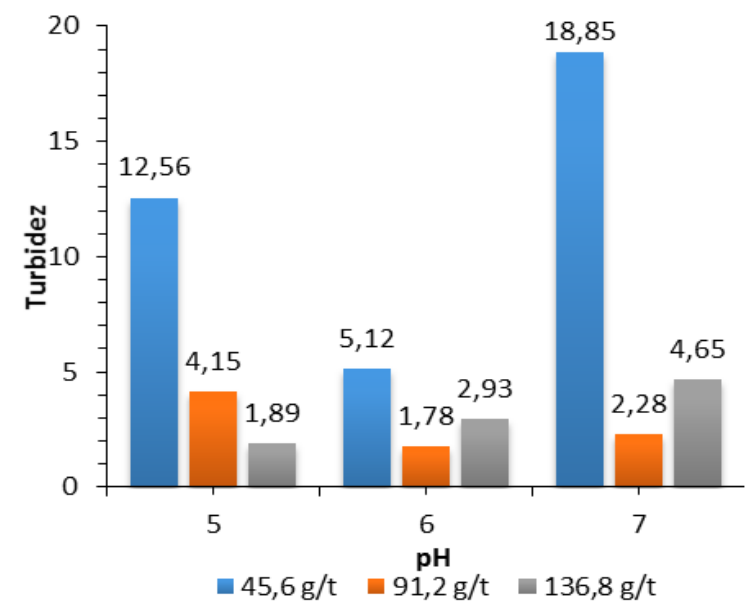

(b)

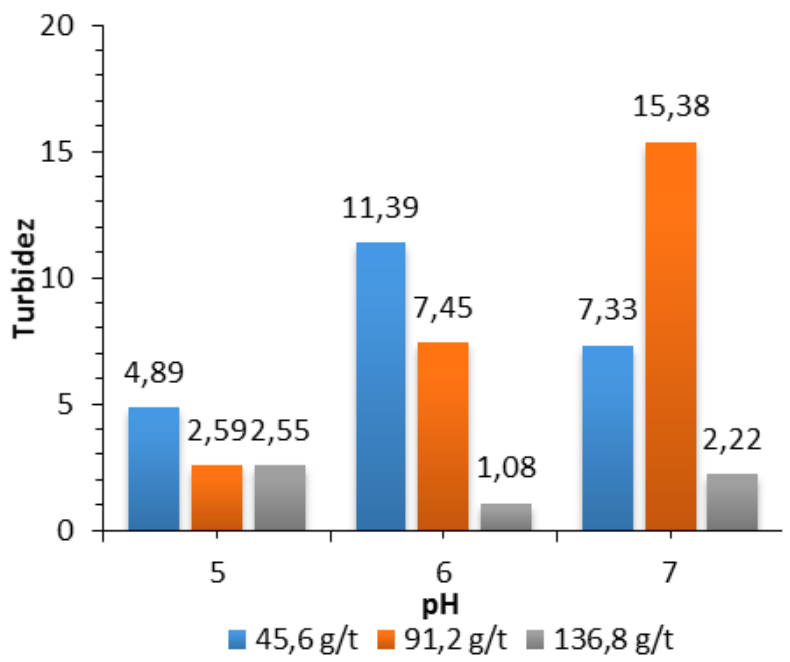

(c)

Figura 4. Variação da turbidez em relação ao pH e dosagens dos floculantes: (a) Superfloc A-100, (b) Superfloc C492 e (c) Magnafloc 351.

\section{CONCLUSÕES}

Observando os resultados obtidos de turbidez conclui-se que cada $\mathrm{pH}$ tem uma dosagem ideal de floculante a ser adicionado. Dosagens de floculante acima deste limite promove a dispersão de material sólido no meio aquoso e a polpa fica, consequentemente, com uma turbidez maior. Os três melhores resultados foram obtidos utilizando o Superfloc A-100, sendo o melhor resultado em pH 5, seguido do pH 7 e por último pH 6, e com concentrações de 136,8, 91,2 e $136,8 \mathrm{~g} / \mathrm{t}$, respectivamente. Supondo que se deseje utilizar outro floculante, tanto o Superfloc C-492 quanto o Magnafloc 351 obtiveram bons resultados em pH 6 e concentração de $91,2 \mathrm{~g} / \mathrm{t}$.

Todos os floculantes utilizados sedimentaram grande parte da vermiculita em até 4 minutos após o início do teste, independente da concentração do floculante ou do pH da polpa. Isso não aconteceu com os testes sem floculante, uma vez que parte da vermiculita não se sedimentou após duas horas de teste. Os melhores resultados foram obtidos em $\mathrm{pH} 7$ nas dosagens 45,6 e 91,2 g/t para o Magnafloc 351, onde obteve-se um aumento da sedimentação na ordem de $604 \%$ em relação ao teste sem adição de floculantes. Contudo, levando-se em 
consideração a turbidez entre estes dois testes, na dosagem de 45,6 g/t chegou-se a um valor menor de turbidez, sendo então o melhor resultado conseguido no quesito altura final da camada compacta após 4 minutos de teste.

Enquanto o Magnafloc 351 (poliacrilamida não iônica) apresentou melhores resultados em termos da altura final da camada compacta, o Superfloc A-100 (poliacrilamida aniônica) apresentou os melhores resultados de turbidez. Este fato se deve ao tipo do floculante utilizado no que tange a sua carga elétrica e ao $\mathrm{pH}$ da polpa. Acredita-se que a variação do $\mathrm{pH}$ tenha gerado diferenças nos testes de sedimentação uma vez que o potencial zeta da vermiculita aumenta com a diminuição do pH, para pH's menores que 8 (SILVA e FROTA, 2012). Levando em consideração os dois quesitos simultaneamente sugere-se a adoção industrial do Magnafloc 351 em $\mathrm{pH} 7$ e dosagem de $91,2 \mathrm{~g} / \mathrm{t}$.

\section{AGRADECIMENTOS}

Os autores agradecem ao apoio financeiro, imprescindível para o desenvolvimento do presente trabalho, das agências brasileiras de fomento à pesquisa CNPq, CAPES, FAPEG e FUNAPE, à Universidade Federal de Goiás, pelo apoio dado ao mesmo e à empresa Brasil Minérios, pela doação de material e liberação da divulgação dos dados da pesquisa.

\section{REFERÊNCIAS}

1. FRANÇA, S. C. A., CASQUEIRA, R. G. Ensaios de sedimentação. In: SAMPAIO, J. A., FRANÇA, S. C. A., BRAGA, P. F. A. Tratamento de Minérios: Práticas Laboratoriais. Rio de Janeiro: CETEM/MCT, 2007. p. 393-408.

2. FRANÇA, S. C. A., MASSARANI, G. Separação sólido-líquido. In: LUZ, A. B., SAMPAIO, J. A., ALMEIDA, S. L. M. (Ed.). Tratamento de Minérios, 5ạ edição. Rio de Janeiro: CETEM/MCT, 2010, p. 637-682.

3. MACHADO, F. B., MOREIRA, C. A., ZANARDO, A, ANDRE, A. C., GODOY, A. M., FERREIRA, J. A., GALEMBECK, T., NARDY, A. J. R., ARTUR, A. C., OLIVEIRA, M.A.F.de. Enciclopédia Multimídia de Minerais. [on-line]. ISBN: 85-89082-11-3 Disponível em http://www.rc.unesp.br/museudpm. Acessado em 01 de junho de 2015.

4. PAULA, R. F. Vermiculita. Departamento Nacional de Produção Mineral, v. 34. p. 122 a 124, 2014.

5. SILVA, A. M., FROTA, H. B. M. Caracterização de vermiculitas com fins de produção de adsorventes seletivos. 52 Congresso Brasileiro de Química, 2012.

6. SVAROVSKY, L. Solid-Liquid Separation. Butterworth \& Co. Ltd, $2^{\text {nd }}$ edition, Bradford-UK, $1981,556 \mathrm{p}$.

7. UGARTE, J. F. O, SAMPAIO, J. A, FRANÇA, S. C. A. Vermiculita. In: LUZ, A. B., LINS, F. F. (Org.) Rochas \& Minerais Industriais: Usos e Especificações. Rio de Janeiro: CETEM/MCT, 2005. p. 677-698. 